\title{
Author Correction: Drug resistance and tolerance in fungi
}

Judith Berman (D) and Damian J. Krysan

Nature Reviews Microbiology (2020) https://doi.org/10.1038/s41579-019-0322-2 Published online 11 February 2020

In Figure 1e of this Review, Hsp90 was incorrectly shown to inhibit calcineurin. The figure has been corrected to indicate that Hsp90 promotes the activity of calcineurin, and the figure legend has been amended accordingly in the HTML and PDF versions of the manuscript. The authors apologize to readers for this error.

https://doi.org/10.1038/s41579-020-0415-y I Published online 29 June 2020

(c) Springer Nature Limited 2020

\section{Author Correction: Genomics and epidemiological surveillance}

\section{Stephanie W. Lo and Dorota Jamrozy}

Nature Reviews Microbiology (2020) https://doi.org/10.1038/s41579-020-0421-0 Published online 20 July 2020

In the Genome Watch article, it was incorrectly stated that the D614 variant replaced a previously established G614 variant. The sentence has been amended to read 'Comparison of different regions revealed consistent patterns of the G614 variant replacing a previously established D614 variant.' The text has been corrected in the HTML and PDF versions of the manuscript. The authors apologize to readers for this error. https://doi.org/10.1038/s41579-020-0428-6 I Published online 28 July 2020

(c) Springer Nature Limited 2020 